Supporting Information for:

\title{
Dip-Pen Patterning and Surface Assembly of Peptide Amphiphiles
}

Hongzhou Jiang and Samuel I. Stupp*

\section{Scanning Electron Microscope (SEM) images of AFM tips}

AFM tips that were not treated with silane and dipped into the PA ink (an aqueous solution containing $0.1 \mathrm{wt} \% \mathrm{PA} \mathrm{1,3.0} \mathrm{vol} \mathrm{\%} \mathrm{glycerin)} \mathrm{as} \mathrm{described} \mathrm{in} \mathrm{the} \mathrm{paper,}$ showed clear formation of nanofiber network, while the AFM tips treated with 2-[methoxy poly(ethyleneoxy)propyl]-trimethoxysilane showed minimal nanofiber formation after dipping into the PA ink.
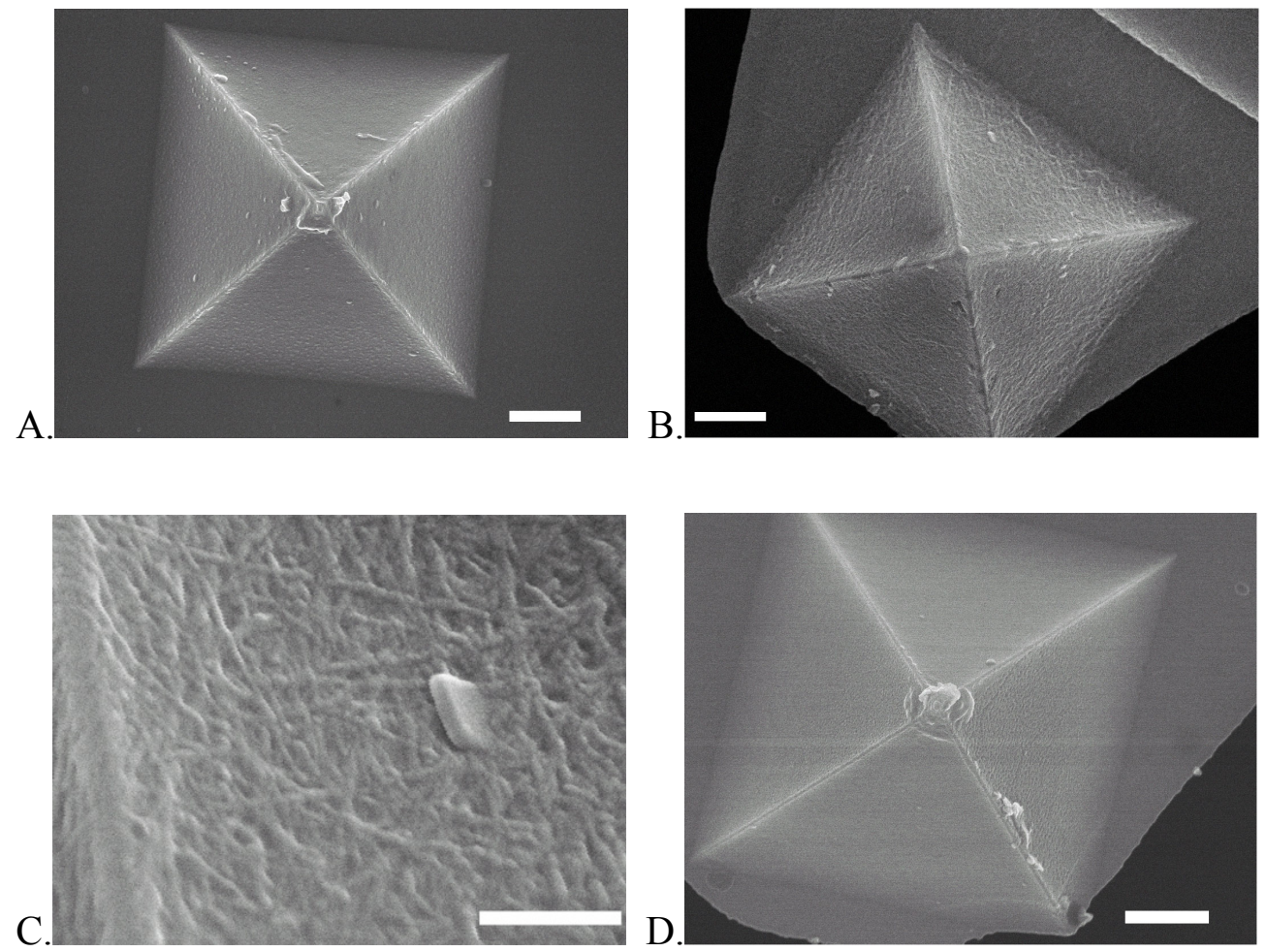

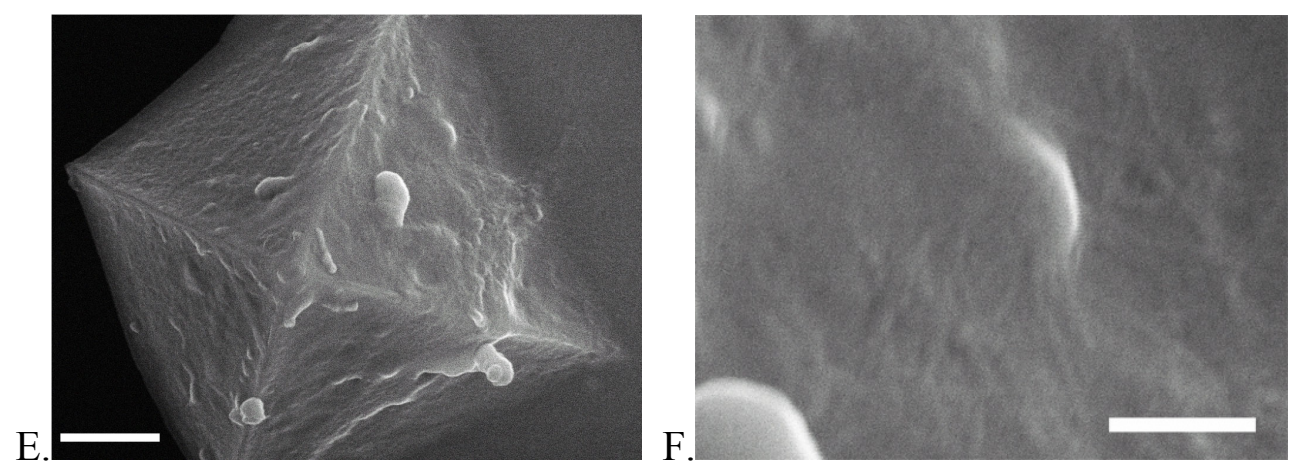

Figure S1. SEM images of (A) untreated $\mathrm{Si}_{3} \mathrm{~N}_{4}$ AFM tip, (B), (C) untreated tip dipped in PA ink, (D) 2-[methoxy poly(ethyleneoxy)propyl]-trimethoxysilane coated tip, (E), (F) PEG-silane coated tip dipped in the PA ink. The scale bars in (A), (B), (D), (E) represent 1 micrometer. The scale bars in (C), (F) represent 300 nanometers. All samples are sputter-coated with $3 \mathrm{~nm}$ of $\mathrm{Au} / \mathrm{Pd}$. The images were collected using a Hitachi S-4500 field emission SEM. 